\title{
Diverticular disease and chronic idiopathic inflammatory bowel disease: associations and masquerades
}

Diverticular disease of the sigmoid colon affects between 35 and $60 \%$ of the Western population over the age of 60 years. ${ }^{12}$ Inflammatory bowel disease (IBD) is also common in the elderly Western population. Although this patient group includes those with a long history of IBD, it is now well accepted that there is a second peak of incidence of IBD in the elderly. ${ }^{3-6}$ It is therefore not surprising that diverticular disease and IBD often coexist. However, Crohn's disease and diverticulosis coexist more often than would be expected by chance, particularly in elderly women. ${ }^{7-10}$ Nevertheless the picture may not be as straightforward as published reports suggest. Pathologically diverticulosis and its local complications may closely mimic both ulcerative colitis and Crohn's disease. A review of published reports suggests that the association between the conditions may be exaggerated. There is increasing recognition of a particular form of IBD that affects the luminal mucosa in the sigmoid colon with diverticular disease. ${ }^{11-15}$ This disease may cause confusion with IBD but a small number of such cases may represent a specific form of IBD.

\section{Diverticulosis and Crohn's disease}

In the older patient, Crohn's disease is more likely to affect the distal colon and anorectum than the proximal colon and small bowel ${ }^{49}$ while the disease may also preferentially involve the sigmoid colon affected by diverticular disease. ${ }^{7-10}$ Crohn's disease of the sigmoid colon may also induce diverticulitis in patients with diverticular disease. ${ }^{8}$ Radiological examination of the sigmoid colon by barium enema may help in the diagnosis of dual pathology. The presence of transmural fissuring and extraluminal longitudinal sinus tracts are the most helpful distinguishing features. ${ }^{7816}$ Endoscopic examination may show signs of Crohn's disease especially aphthous ulcers. Caution may be needed as aphthous ulcers do occur in diverticulosis associated mucosal inflammation and are not, in this situation, specific for Crohn's disease. ${ }^{14}$

While there are characteristic clinical, endoscopic, and radiological features of Crohn's disease, the diagnosis is usually only fully established by pathological assessment. The three pathological hallmarks of the disease are transmural inflammation, epithelioid cell granulomata, and fissuring or fistula formation. While biopsies may strongly suggest the diagnosis and are sometimes diagnostic, a definitive diagnosis of Crohn's disease is often only made at the time of intestinal resection. It is clear from several papers describing the association of sigmoid Crohn's disease and diverticulosis that the diagnosis was indeed made at the time of resection. ${ }^{79} 10$ All three pathological hallmarks of Crohn's disease may be seen as a result of complicated diverticular disease alone. ${ }^{11}$ Transmural inflammation and fissuring/fistulation may be associated with diverticulitis and peridiverticulitis while granulomata can occur as a reaction to intraluminal material escaping into the tissues adjacent to diverticula. Even granuloma- tous cryptitis, a histiocytic and granulomatous reaction to disruptive crypt abscesses in the mucosa, a characteristic feature of Crohn's disease, ${ }^{17}{ }^{18}$ may accompany the luminal mucosal inflammatory response that occurs in diverticular disease. ${ }^{14}$

Patients with diverticulosis are generally in an older age group and may have coexistent atheromatous disease. The impact of relative ischaemia and changes in bacterial flora due to diverticulosis may cause the Crohn's-like inflammatory response in the sigmoid colon (Gledhill A, Dixon MF. Crohn's-like reaction in diverticular disease (data in preparation)). Similar Crohn's-like immunological responses are well recognised in tissues adjacent to colonic cancer. ${ }^{19}$

The prognosis of patients purported to show coexistence of Crohn's disease and diverticular disease in published reports seems remarkably good with many patients showing no evidence of recrudescence of Crohn's disease elsewhere. ${ }^{79} 10$ This suggests that some of these cases do simply represent complicated diverticulosis with pathological mimicry of Crohn's disease in the sigmoid resection specimen. The author strongly believes that, while there is some evidence to suggest a link between sigmoid Crohn's disease and diverticulosis, substantiation of a diagnosis of Crohn's disease should be sought by investigation of the remaining gastrointestinal tract in cases where apparent Crohn's disease complicates diverticular disease of the sigmoid colon. ${ }^{11}$

\section{Luminal inflammation in diverticulosis}

Diverticular disease has previously only been considered an inflammatory condition when inflammation of the diverticula, diverticulitis, and the adjacent subserosal tissues, peridiverticulitis, were present. It is increasingly realised that luminal mucosal inflammation may occur in diverticular disease although, given the frequency of diverticulosis, this form of inflammation seems to be comparatively unusual. ${ }^{12-14}$ Various epithets have been given to the condition including diverticular colitis, segmental colitis, sigmoiditis, and crescentic colitis. The first of these would seem the most preferable. Rectal bleeding is a characteristic clinical presentation. ${ }^{12-14}$ Endoscopically intramucosal haemorrhage, congestion, and granularity can affect the mucosa away from the diverticula ${ }^{13}$ and especially the crescentic mucosal folds. ${ }^{12}$ In some patients the disease is more continuous within the sigmoid colon. ${ }^{1314}$ The unifying attribute is that the disease is wholly confined to the segment affected by diverticular disease. ${ }^{12-14}$

Diverticular colitis has been associated with various pathogenetic mechanisms. Diverticulosis is accompanied by bowel shortening and mucosal redundancy. The pressure effects allied to the excessive mucosa induce mucosal prolapse and polypoid change. ${ }^{2021}$ Pathological examination of these polypoid lesions shows inflammatory changes but with the characteristic features of mucosal prolapse. ${ }^{12} 2122$ Such 
polypoid mucosal prolapse with inflammation may occur in pre-diverticular disease, when the muscular changes of the disease are present but diverticula themselves have not yet developed. ${ }^{20}$ By no means all cases with inflammation in the luminal mucosa can be ascribed to prolapsing mucosal folds for in many cases the endoscopic and pathological appearances are unlike those of mucosal prolapse and pathological changes vary from non-specific inflammation $^{12} 23$ through to intense active inflammation with crypt abscesses, crypt architectural distortion, and pronounced chronic inflammation, closely mimicking active chronic ulcerative colitis. ${ }^{12-15} 22$ Suggested mechanisms for this active inflammatory condition of the sigmoid colonic mucosa have included relative ischaemia of the sigmoid colon, increased exposure to intraluminal antigens and toxins, and changes in bacterial flora related to stasis. ${ }^{12}$ Many of these cases of diverticular colitis respond favourably to treatment similar to that given for IBD. ${ }^{12-15}$

\section{Diverticulosis and ulcerative colitis}

While diverticular colitis may closely resemble ulcerative colitis pathologically, in most cases a rectal biopsy specimen is normal and there is no other preceding or succeeding evidence of IBD outside the sigmoid colon. ${ }^{12-1522}$ However, two recent series have reported five cases presenting with diverticular colitis with pathological features, in the sigmoid colonic mucosa, identical to ulcerative colitis but with endoscopically and histologically normal rectal mucosa, who have subsequently developed classic distal ulcerative colitis with characteristic rectal involvement. ${ }^{12} 14$ These patients have responded well to similar treatment to that of IBD. 1214

A diagnosis of ulcerative colitis, in the absence of demonstrable abnormality of the rectum, is, in traditional view, untenable but relative sparing of the rectum is now well described. ${ }^{24}{ }^{25}$ Could these cases of apparent IBD in older patients represent a distinct form of chronic ulcerative colitis, which seems to start in the sigmoid colon affected by diverticular disease and progress to more classic ulcerative colitis? Given the apparent rarity of such cases, perhaps of more interest is the potential evidence these cases provide us with in terms of the pathogenesis of ulcerative colitis. Pathologists are well aware of the focal disease seen in ulcerative colitis in blind-ending parts of the large intestine such as the appendix ${ }^{26}$ and the caecum ${ }^{27}$ with histologically normal proximal colon. Ulcerative colitis is primarily a disease of the rectum where a degree of faecal stasis is inevitable. There is current interest in the role of faecal bacterial mucolytic enzyme activity, especially sulphatases and sialidases, and mucolysis in the pathogenesis of ulcerative colitis. ${ }^{28} 29$ Faecal stasis and activity of these bacterial enzymes could be the link, in ulcerative colitis, between involvement of the rectum and disease in these other blind-ending structures, the caecum, appendix, and sigmoid diverticula. Could such a theorem also explain the apparent protective effect of appendicectomy against ulcerative colitis? ${ }^{30}$

\section{Conclusion}

Diverticular disease may be associated with complex inflammatory characteristics that may closely mimic IBD. Clinical evidence would suggest that the coexistence of diverticulosis and Crohn's disease is commoner than the prevalence of either disease would suggest while pathological evidence intimates that the association may be exaggerated. The situation is just as uncertain with ulcerative colitis, because of mimicry of that disease by luminal inflammation in diverticular disease. In some patients the latter may represent a specific form of inflammatory bowel disease, which responds well to treatment that is effective in IBD. Occasional cases of diverticular colitis suggest an intriguing relation between diverticular colitis and ulcerative colitis, which may provide insights into the pathogenesis of ulcerative colitis.

Gloucester Gastroenterology Group,

NEIL A SHEPHERD

Gloucestershire Royal Hospital,

Gloucester GL1 3NN

1 Manousos ON, Truelove SC, Lumsden K. Prevalence of colonic diverticulosis in the general population of Oxford area. BMF 1967; 3: 762-3.

2 Hughes LE. Postmortem survey of diverticular disease of the colon. Gut 1969; 10: 336-51.

3 Shapiro PA, Peppercorn MA, Antonioli DA, Joffe N, Goldman H. Crohn's disease in the elderly. Am $\mathcal{f}$ Gastroenterol 1981; 76: 132-7.

4 Carr N, Schofield PF. Inflammatory bowel disease in the older patient. $\mathrm{Br} F$ Surg 1982; 69: 223-5.

5 Tchircow G, Lavery IC, Fazio VW. Crohn's disease in the elderly. Dis Colon Rectum 1983; 26: 177-81.

6 Zimmerman J, Gavish D, Rachmilewitz D. Early and late onset ulcerative colitis. Distinct clinical features. F Clin Gastroenterol 1985; 7: 492-8.

7 Schmidt GT, Lennard-Jones JE, Morson BC, Young AC. Crohn's disease of the colon and its distinction from diverticulitis. Gut 1968; 9: 7-16.

8 Meyers MA, Alonso DR, Morson BC, Bartram C. Pathogenesis of diverticulitis complicating granulomatous colitis. Gastroenterology 1978; 74: $24-31$.

9 Berman IR, Corman ML, Coller JA, Veidenheimer MC. Late onset Crohn's disease in patients with colonic diverticular disease. Dis Colon Rectum 1979; 22: 524-9.

10 McCue J, Coppen MJ, Rasbridge SA, Lock MR. Coexistent Crohn's disease and sigmoid diverticulosis. Postgrad Med $\mathcal{F}$ 1989; 65: 636-9.

11 Shepherd NA. Pathological mimics of chronic inflammatory bowel disease. Clin Pathol 1991; 44: 726-33.

12 Gore S, Shepherd NA, Wilkinson SP. Endoscopic crescentic fold disease of the sigmoid colon: the clinical and histopathological spectrum of a distinctive endoscopic appearance. Int f Colorect Dis 1992; 7: 76-81.

13 Peppercorn MA. Drug-responsive chronic segmental colitis associated with diverticula: a clinical syndrome in the elderly. Am $\mathcal{F}$ Gastroenterol 1992; 87: 609-12.

14 Makapugay LM, Dean PJ. Diverticular disease-associated chronic colitis. Am $\mathcal{F}$ Surg Pathol 1996; 20: 94-102.

15 Hart J, Baert F, Hanauer S. Sigmoiditis: a clinical syndrome with a spectrum of pathological features, including a distinctive form of IBD. Mod Pathol 1995; 8: 62A

16 Marshak RH, Janowitz HD, Present DH. Granulomatous colitis in association with diverticula. N Engl f Med 1970; 283: 1080-4

17 Morson BC, Dawson IMP, Day DW, Jass JR, Price AB, Williams GT. Inflammatory disorders. In: Morson $\mathcal{E}$ Dawson's gastrointestinal pathology, 3rd ed. Oxford: Blackwell Scientific, 1990: 521 .

18 Lee FD, Maguire C, Obeidat W, Russell RI. The significance of cryptolytic lesions in inflammatory bowel disease. Gut 1995; 37: A21.

19 Graham DM, Appelman HD. Crohn's-like lymphoid reaction and colorectal cancer: a potential histologic prognosticator. Mod Pathol 1990; 3: 332-5.

20 Mathus-Vliegen EMH, Tytgat GNJ. Polyp-simulating mucosal prolapse in (pre-) diverticular disease. Endoscopy 1986; 18: 84-6.

21 Kelly JK. Polypoid prolapsing mucosal folds in diverticular disease. Am $\mathcal{f}$ Surg Pathol 1991; 15: 871-8.

22 Cawthorn SJ, Gibbs NM, Marks CG. Segmental colitis: a new complication of diverticular colitis. Gut 1983; 24: A500.

23 Sladen GE, Filipe MI. Is segmental colitis a complication of diverticular disease? Dis Colon Rectum 1984; 27: 513-4.

24 Burnham WR, Ansell ID, Langman MJ. Normal sigmoidoscopic findings in severe ulcerative colitis: an important and common occurrence. Gut 1980; 21: A460.

25 Spiliadis CA, Spiliadis CA, Lennard-Jones JE. Ulcerative colitis with relative sparing of the rectum. Clinical features, histology and prognosis. Dis Colon Rectum 1987; 30: 334-6.

26 Davison AM, Dixon MF. The appendix as a 'skip lesion' in ulcerative colitis. Histopathology 1990; 16: 93-5.

27 von Herbay A, Starlinger M. Pathologie der idiopathischen chronischendzundlichen Darmerkrankungen. In: Alder G, ed. Morbus Crohn Colitis endzundlichen Darmerkrankungen. In: Alder G,

28 Corfield AP, Williams AJK, Clamp JR, Wagner SA, Mountford RA. Degradation of bacterial enzymes of colonic mucus from normal subjects and patients with inflammatory bowel disease: the role of sialic acid metabolism and the detection of a novel esterase. Clin Sci 1988; 74: 71-8.

29 Tsai HH, Dwarakanath AD, Hart CA, Milton JD, Rhodes JM. Increased faecal mucin sulphatase activity in ulcerative colitis: a potential target for treatment. Gut 1995; 36: 570-6.

30 Rutgeerts P, d'Haerns G, Hiele M, Geboes K, Vantrappen G. Appendectomy protects against ulcerative colitis. Gastroenterology 1994; 106: $1251-3$. 